\title{
Rectal and colonic studies after resection of the sigmoid for diverticular disease
}

T. G. PARKS

From the Department of Surgery, Queen's University of Belfast, and St. Mark's Hospital, London

SUMMARY Spontaneous basal rectal activity, recorded after resection of the sigmoid colon for diverticular disease, was more than twice the normal.

The rectum of post-resection cases yielded a markedly exaggerated overall response to prostigmine, in addition to producing abundant fast wave patterns.

The response to stretch of the apparently normal colonic muscle remaining after resection of the sigmoid for diverticular disease resembled unresected diverticular segments, though less in degree, suggesting that a fundamental disorder of colonic muscle may be involved in the aetiology of colonic diverticula.

For many years it has generally been accepted that a muscular disorder occurs in association with diverticula of the colon (Keith, 1910; Edwards, 1939; Morson, 1963; Williams, 1965), but whether this abnormality is primary or secondary is still controversial. In recent years abnormal motility responses have been demonstrated in diverticular disease in regions bearing diverticula (Painter and Truelove, 1964; Arfwidsson, 1964; Parks and Connell, 1969a). Whether these disturbances of motor function occur in other regions of the colon free from diverticula is less certain.

The present study was undertaken to assess the motor function after resection of the diverticular segment of the colon. There have been no previous reports of pressure studies following sigmoid resection with which a comparison can be made.
The main aims of the study were $(a)$ to compare colonic and rectal pressure activity under resting conditions in control subjects, in patients with unresected diverticular disease, and in patients with previous sigmoid resection for diverticular disease; (b) to compare the colonic and rectal responses to food, to prostigmine, and to distension in these groups.

\section{Methods and Patients Studied}

Investigations were carried out on 23 patients in whom the segment bearing diverticula had been excised and the bowel anastomosed at least six months previously. Removal of the a ffected region was judged to be complete on the basis of radiological and operative findings. Two separate studies were undertaken. 
SERIES 1

The first series consisted of nine patients in whom colonic pressures were measured using miniature balloons connected to a multichannel electromanometer (Schwarzer München) via fine polyethylene tubing. Using a sigmoidoscope the upper balloon was placed above the anastomosis at 22 to $25 \mathrm{~cm}$ from the anus. The lower balloon lay in the rectum below the anastomosis 12 to $15 \mathrm{~cm}$ from the anus. Tracings were obtained for 30-minute periods under resting conditions following the physiological stimulus of eating and the pharmacological stimulus of an intramuscular injection of $0.5 \mathrm{mg}$ of prostigmine. The following parameters were analysed: (1) The percentage of the time during which activity occurred; (2) the mean amplitude of the individual waves $\left(\mathrm{cm} \mathrm{H}_{2} \mathrm{O}\right)$; (3) The product of 1 and 2, which gives an index of the overall activity; (4) The percentage of the time of analysis occupied by fast waves (ie, 5 or more waves/minute).

\begin{tabular}{|c|c|c|c|}
\hline & $\begin{array}{l}\text { Control } \\
\text { Subjects } \\
(19)^{1}\end{array}$ & $\begin{array}{l}\text { Medical } \\
\text { Diverticular } \\
\text { Disease } \\
(25)^{1}\end{array}$ & $\begin{array}{l}\text { Post-resection } \\
\text { Diverticular } \\
\text { Disease } \\
\text { (9) }\end{array}$ \\
\hline $\begin{array}{l}\text { Basal } \\
\text { Duration of activity } \\
\text { Mean amplitude } \\
\text { Product }\end{array}$ & $\begin{array}{r}45 \cdot 8 \\
14.8 \\
528 \cdot 3\end{array}$ & $\begin{array}{r}26.7 \\
15.6 \\
470.4\end{array}$ & $\begin{array}{r}35.5 \\
14.1 \\
521.8\end{array}$ \\
\hline $\begin{array}{l}\text { After Lunch } \\
\text { Duration of activity } \\
\text { Mean amplitude } \\
\text { Product }\end{array}$ & $\begin{array}{r}55 \cdot 2 \\
16.4 \\
926.7\end{array}$ & $\begin{array}{r}39 \cdot 6 \\
19.2 \\
819.5\end{array}$ & $\begin{array}{r}51 \cdot 8 \\
18 \cdot 3 \\
1020 \cdot 1\end{array}$ \\
\hline $\begin{array}{l}\text { After Prostigmine } \\
\text { Duration of activity } \\
\text { Mean amplitude } \\
\text { Product }\end{array}$ & $\begin{array}{r}77.8 \\
22.5 \\
1870.3\end{array}$ & $\begin{array}{r}59 \cdot 1 \\
29 \cdot 5 \\
2001.9\end{array}$ & $\begin{array}{r}65.6 \\
23.5 \\
1621.3\end{array}$ \\
\hline
\end{tabular}

Table I Comparison of the motility at $25 \mathrm{~cm}$ from the anus in resected and non-resected cases of diverticular disease

'From 'Motility s tudies in diverticular disease of the colon' (Gut, 10, 534-536).

\begin{tabular}{|c|c|c|c|}
\hline & $\begin{array}{l}\text { Control } \\
\text { Subjects } \\
(19)^{1}\end{array}$ & $\begin{array}{l}\text { Medical } \\
\text { Diverticular } \\
\text { Disease } \\
(25)^{1}\end{array}$ & $\begin{array}{l}\text { Post-resection } \\
\text { Diverticular } \\
\text { Disease } \\
\text { (9) }\end{array}$ \\
\hline $\begin{array}{l}\text { Basal } \\
\text { Duration of activity } \\
\text { Mean amplitude } \\
\text { Product }\end{array}$ & $\begin{array}{r}32 \cdot 3 \\
6 \cdot 6 \\
237 \cdot 4\end{array}$ & $\begin{array}{r}22.4 \\
9.4 \\
330.0\end{array}$ & $\begin{array}{r}34.5 \\
17 \cdot 7 \\
615 \cdot 8\end{array}$ \\
\hline $\begin{array}{l}\text { After Lunch } \\
\text { Duration of activity } \\
\text { Mean amplitude } \\
\text { Product }\end{array}$ & $\begin{array}{r}38 \cdot 4 \\
7 \cdot 5 \\
317.6\end{array}$ & $\begin{array}{r}23 \cdot 8 \\
10 \cdot 2 \\
399 \cdot 6\end{array}$ & $\begin{array}{r}43 \cdot 2 \\
16 \cdot 6 \\
683 \cdot 6\end{array}$ \\
\hline $\begin{array}{l}\text { After Prostigmine } \\
\text { Duration of activity } \\
\text { Mean amplitude } \\
\text { Product }\end{array}$ & $\begin{array}{r}67 \cdot 6 \\
11.3 \\
865.8\end{array}$ & $\begin{array}{r}38 \cdot 1 \\
11 \cdot 3 \\
556 \cdot 7\end{array}$ & $\begin{array}{r}62.1 \\
21.8 \\
1528.0\end{array}$ \\
\hline
\end{tabular}

Table II Comparison of the rectal motility in resected and non-resected cases of diverticular disease

'From 'Motility studies in diverticular disease of the colon' (Gut 10, 534-536).
A comparison was made with the results of $\Omega$ similar studies on 25 patients with unresected diverticular disease and 19 control subjects (Parks and Connell, 1969a). It is recognized that recordings above the anastomosis in postresection cases at $22 \mathrm{~cm}$ from the anus detect motility in a different anatomical segment of the bowel, ie, descending colon, from that of patients or persons with intact colons. In addition, patients who had operations were usually more severely affected than those who were treated conservatively.

\section{SERIES 2}

This was a series of studies in 14 persons after resection of the diverticular segment in whom the response of the colonic muscle to a stretching force was measured. A large balloon connected to a water manometer was placed in the colon above the anastomosis at a point 22 to $25 \mathrm{~cm}$ from the anus. The resistance of the colonic wall to stretch was noted as the balloon was distended using increments of $20 \mathrm{ml}$ of water at body temperature. Rectal distension was carried out in 11 patients using increments of $40 \mathrm{ml}$ of water. The findings were compared with distension studies in patients with unresected diverticular disease and control subjects (Parks and Connell, 1969b).

\section{Results}

\section{SERIES 1}

The results of analyses of the miniature balloon studies are set out for the colon in Table $I$ and for the rectum in Table II.

\section{Basal motility}

After resection of the sigmoid the predominant wave remained simple, indicating the presence of segmentation similar to that found in the $N$ preoperative state and control subjects (Figure 1). The overall colonic activity in the resected case was the same as that in the unresected case of diverticular disease. The mean amplitude of the waves, and also the overall activity of the rectum in post-resection cases was approximately twice that of the unresected cases.

\section{Effect of eating}

After operation the colon responded to a standard meal in a similar way to the unresected cases and the control subjects. In the rectum the percentage increase over basal activity was slight in all groups.

\section{Effect of prostigmine}

The mean colonic activity following intramuscular prostigmine in the surgical cases of diverticular disease was not markedly different 
from the non-surgical patients and the controls.

The rectum responded powerfully to prostigmine in the post-resection cases and this was reflected by both the duration of activity and the amplitude of the waves. The total activity was almost three times that of the non-surgical cases of diverticular disease and almost twice that of the controls.
The percentage of the time of analysis occupied by fast waves is set out for the three groups in Table III. In patients with previous resections, fast waves in the colon were less common, especially after prostigmine, than in the nonresected cases. On the other hand, in the rectum of post-resection patients, which was generally hyperactive, fast waves (Fig. 1) were present for
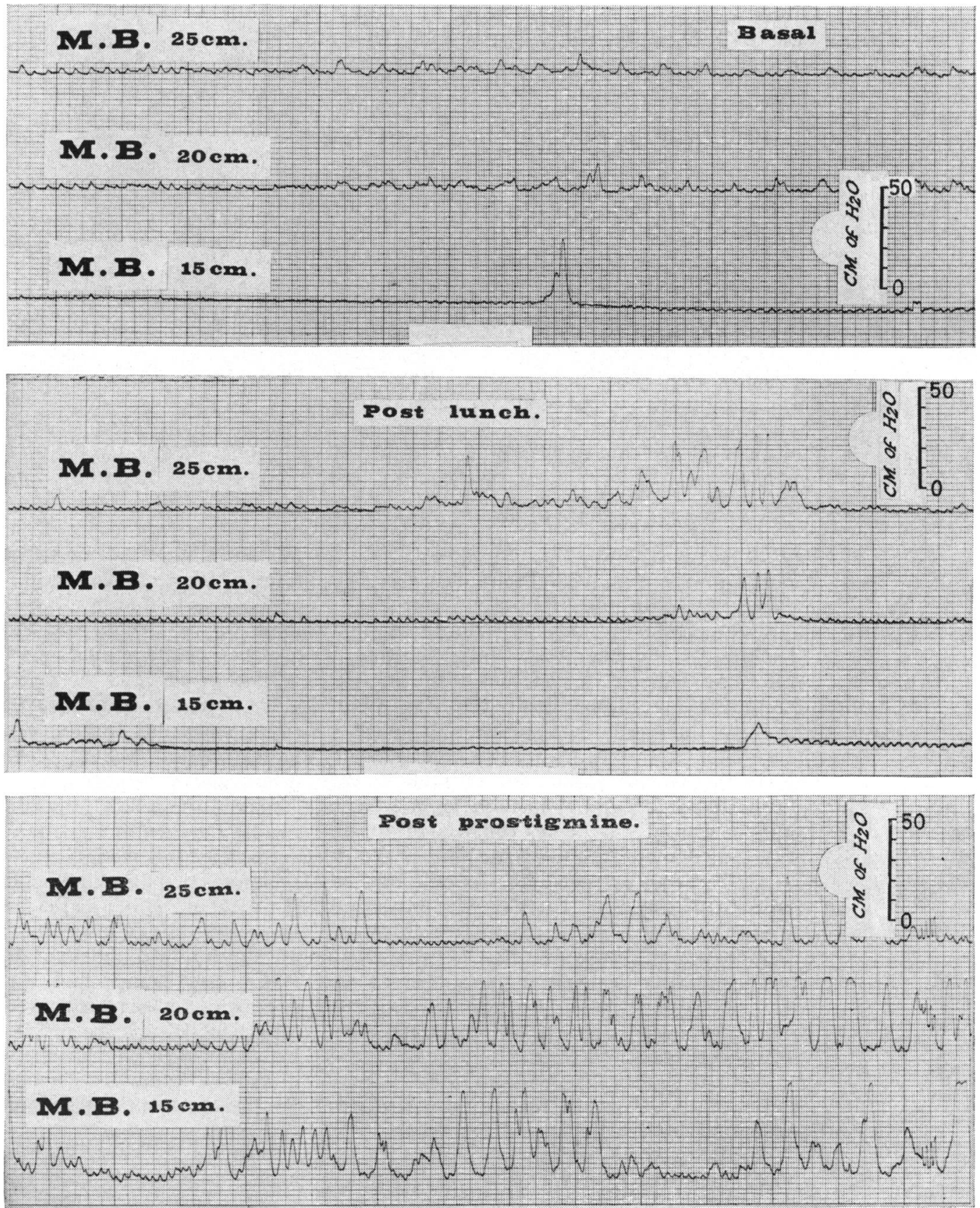

Fig. 1 Motility record after resection of the sigmoid colon for diverticular disease: (a) under basal conditions; (b) after eating; (c) after prostigmine $0.5 \mathrm{mg}$ intramuscularly. 


\begin{tabular}{llll}
\hline & $\begin{array}{l}\text { Control } \\
\text { Subjects } \\
(19)^{1}\end{array}$ & $\begin{array}{l}\text { Medical } \\
\text { Diverticular } \\
\text { Disease } \\
(25)^{1}\end{array}$ & $\begin{array}{l}\text { Post-resection } \\
\text { Diverticular } \\
\text { Disease } \\
(9)\end{array}$ \\
\hline Colon & & & \\
Basal & & $2 \cdot 7$ & 3.9 \\
After lunch & $2 \cdot 6$ & $6 \cdot 4$ & $6 \cdot 8$ \\
After prostigmine & 5.0 & 14.1 & $7 \cdot 1$ \\
Rectum & 5.6 & & \\
Basal & & 2.0 & 4.3 \\
After lunch & 3.3 & 2.0 & 6.8 \\
After prostigmine & 3.2 & 14.0 & 19.0 \\
\hline
\end{tabular}

Table III Percentage of time occupied by fast waves 'From 'Motility studies in diverticular disease of the colon' (Gilt, 10, 534-536).

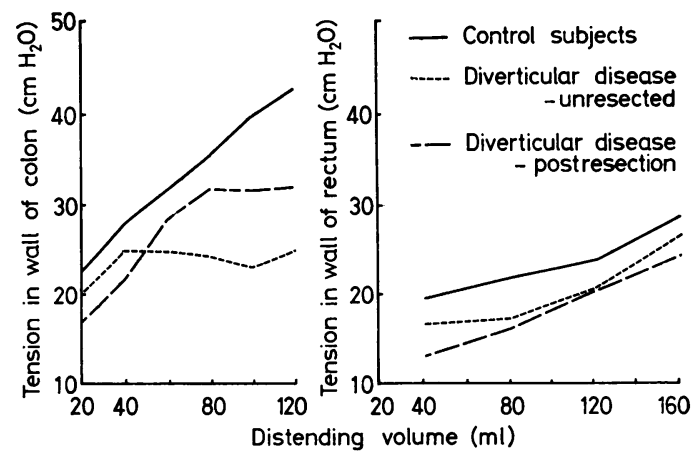

Fig. 2 Volume/pressure relationships: (left) during 옥 distension of the colon at $22 \mathrm{~cm}$ from the anus, (right) during distension of the upper rectum.

\section{Discussion}

a higher proportion of the analysis time. This and after prostigmine.

\section{SERIES 2}

\section{Effect of distension}

The volume/pressure relationships during colonic and rectal distension are shown in Figure 2.

After colonic resection the average tension developed in the colonic wall in response to a distending balloon in the lumen of the gut increased progressively initially but when $80 \mathrm{ml}$ or more was used there was a plateau effect (Figure 2). This contrasts with the control group where the average tension for 11 subjects was higher and was found to increase progressively, with increasing distending volumes of up to 120 millitres. On the other hand, the curve for the patients who had sigmoid resection compared more closely with that of patients with unresected diverticular disease where the tension developed in response was much lower than in the controls, particularly with higher distending volumes; from $40 \mathrm{ml}$ onwards there was a plateau effect. When colonic distension using $120 \mathrm{ml}$ was reached the difference between post-resection and control groups was statistically significant $(0.05>\mathrm{P}>$ 0.02 ) but the difference between post-resection and unresected groups was not significant.

The rectal response to distension was similar in all three groups in that there was a gradual rise in tone with increasing distending volumes, and, although values were slightly lower than normal in both resected and unresected cases of diverticular disease, there was no significant difference in the three groups.
While colonic muscular activity after sigmoid resection is similar to that in controls in a number of respects, deviations from normal do occur. The most striking feature noted in the colon of post-resection cases of diverticular disease was the diminished resistance to a distending force which resembles the response in the unresected cases, though it is less in degree. Again, there was a slightly increased tendency to a fast wave pattern after prostigmine as is seen $\bar{\sigma}$ in unresected cases of diverticular disease. It $\underline{3}$. seems that in some cases, at least, colonic muscle of abnormality and disturbance of muscular func- $₹$ tions persist in regions of the colon in which 9

diverticula are absent.
Arfwidsson (1964) thought that a primary muscle abnormality exists in diverticular disease, $\bar{N}$ and carried out motility studies on patients with symptoms similar to those of diverticular disease, $\widetilde{N}$ but without radiological evidence of diverticula. $\omega$ He produced motility patterns similar to those of patients with colonic diverticula. Morson 0 (1963) has shown that the most consistent $\stackrel{\Phi}{\Phi}$ finding in 155 surgically resected specimens of 'diverticulitis' was the muscle abnormality, and his series included four specimens in which no $\underset{\mathbb{D}}{\vec{D}}$ diverticula could be demonstrated yet muscle $\frac{?}{\mathbb{D}}$ thickening was present in every case. Four cases $\varrho$ of idiopathic muscular strictures of the sigmoid resembling the muscular thickening of diverti- 8 cular disease, have been reported recently by Cassano and Torsoli (1968).

Painter and Truelove (1964) found that, in response to a therapeutic dose of morphine or an injection of prostigmine, the diverticula-bearing segments showed an excessive pressure 
activity while normal segments in the same patients gave a normal response. Thus, according to these workers, the area of the colon affected by diverticular disease acts differently from the rest of the colon.

It is my belief that the segments of colon free from diverticula in patients with resected diverticular disease are not normal, and do not react normally to a stretching force. The muscle in such segments has certain resemblances to diverticula-bearing segments, suggesting that there is a primary muscular abnormality which exists before diverticula make their appearance.

The observation of markedly increased activity in the rectum below the anastomotic line was of considerable interest. It seems that some inhibitory mechanism to rectal motility has been disturbed by operative intervention. The division of the pelvic mesocolon and blood vessels to the rectosigmoid region, and also, possibly in some cases, interference with the presacral fibres, may ablate part of the sympathetic supply to the upper rectum, and thus account for the rectal hyperactivity demonstrated after sigmoid resection. On the other hand, it has been suggested that the sigmoid has a normal restraining influence on the onward passage of faeces (Connell, 1961). The loss of this mechanism must throw an added load on the continence mechanisms of the rectum, of which the fast wave activity detected in this study may be a part.

It is a pleasure to thank $\operatorname{Dr} \mathrm{A}$. M. Connell for consistent, helpful advice throughout the study, and appreciation is also due to the consultants of the Royal Victoria Hospital, Belfast, and St Mark's Hospital, London, for permission to study patients under their care.
References

Arfwidsson S. (1964). Pathogenesis of multiple diverticula of the sigmoid colon in diverticular disease. Acta. chir. scand., Suppl., 342.

Cassano, C., and Torsoli, A. (1968). Idiopathic muscular strictures of the sigmoid colon. Gut, 9, 325-331.

Connell, A. M.(1961). The motility of the pelvic colon. I. Motility in normals and in patients with asymptomatic duodenal ulcer. Gut, 2, 175-186.

Edwards, H. C. (1939). Diverticula and Diverticulitis of the Intestine. Wright, Bristol.

Keith, A. (1910). Diverticula of the alimentary tract of congenital or of obscure origin. Brit. med. J., 1, 376-380.

Morson, B. C. (1963). The muscle abnormality in diverticular disease of the colon. Proc. roy. Soc. Med., 56, 798-800.

Painter, N. S., and Truelove, S. C. (1964). The intraluminal pressure patterns in diverticulosis of the colon. Gut, 5, 201-213, 365-373.

Parks, T. G., and Connell, A. M. (1969a). Motility studies in diverticular disease of the colon. I. Basal activity and response to food assessed by open-ended tube and miniature balloon techniques. Gut, 10, 534-538.

Parks, T. G., and Connell, A. M. (1969b). Motility studies in diverticular disease of the colon. II. Effect of colonic and rectal distension. Gut, 10, 538-542.

Williams, I. (1965). The resemblance of diverticular disease of the colon to a myostatic contracture. Brit. J. Radiol., 38, 437-443. 